\title{
Consumo de forragem por cordeiras suplementadas em pastagem de milheto
}

\author{
Forage intake by supplemented lambs on pearl millet pasture
}

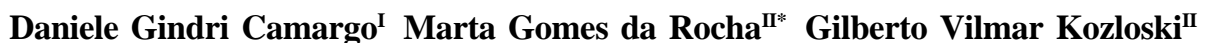 \\ Denise Gomes Elejalde ${ }^{\mathrm{I}}$ Carolina Bremm ${ }^{\mathrm{I}}$ Luciana Pötter $^{\mathrm{II}}$ Aline Tatiane Nunes da Rosa ${ }^{\mathrm{II}}$ \\ Renato Alves de Oliveira Neto ${ }^{\text {III }}$
}

RESUMO

Este trabalho foi conduzido para avaliar a influência de níveis de suplemento $(0,0 ; 0,5 ; 1,0$ e $1,5 \%$ em relação ao peso vivo $(P V)$ ) sobre o consumo de forragem por cordeiras de raças de corte, em pastagem de milheto (Pennisetum americanum (L.) Leeke). O consumo de forragem foi condicionado pelos níveis de suplemento somente no início da utilização da pastagem (dias um-21) e a máxima ingestão de matéria seca ocorreu quando as cordeiras receberam suplemento na proporção de $0,84 \%$ do PV. A ação do suplemento sobre o ganho diário médio (GDM) e o ganho de peso vivo (GPV) foi observada somente na metade e no final do ciclo do pasto (dias 22-64). O consumo e o desempenho de cordeiras em pastagem de milheto mostram maior dependência do estádio fenológico da pastagem do que do recebimento de suplemento.

Palavras-chave: fibra em detergente neutro indigestível, Ile de France $x$ Texel, óxido de cromo, Pennisetum americanum.

\section{ABSTRACT}

This research evaluated the influence of different levels of supplement $(0.0 ; 0.5 ; 1.0$ and $1.5 \%$ in relation to the live weight $(L W))$ on the forage intake of beef lambs, in Pearl millet (Pennisetum americanum (L.) Leeke) pasture. The forage intake was conditioned by the levels of supplement only at the beginning of the pasture utilization (days 1-21), with maximum ingestion of dry matter when lambs received supplement at the ratio of $0.84 \%$ of the $L W$. The influence of the levels of supplement on the daily weight gain and live weight gain was observed only in the half and in the end of the cycle of the pasture (days 22-64).The intake and performance of lambs in
Pearl millet are more dependent on the phenological stage of the pasture rather than the level of supplement received.

Key words: chromic oxide, Ile de France x Texel, indigestible neutral detergent fiber, Pennisetum americanum.

\section{INTRODUÇÃO}

O rebanho de ovinos do Rio Grande do Sul é o maior do país, com aproximadamente quatro milhões de cabeças, cerca de $23,53 \%$ do rebanho brasileiro (ANUALPEC, 2006). Esse rebanho está distribuído em grande número de propriedades rurais do Estado, sendo que o sistema criatório é feito de forma extensiva. Durante o ano, a maior parte do rebanho permanece em pastagem nativa, com restrita disponibilidade de área, o que limita o desempenho de categorias nutricionalmente exigentes.

A pastagem de milheto (Pennisetum americanum (L.) Leeke), no verão, é uma alternativa para o uso da pastagem nativa. Essa espécie produz até cinco vezes mais forragem que o campo nativo (RIZO et al., 2004) e permite incrementar o ganho de peso vivo por área e a taxa de lotação. Em pastejo, o valor bromatológico do milheto varia no decorrer do seu ciclo e o valor dos ganhos de peso realizados pelos animais não se mantém constante (SANTOS et al., 2005). Nessas condições, a suplementação pode ser

IPrograma de Pós-graduação em Zootecnia, Universidade Federal de Santa Maria (UFSM), Santa Maria, RS, Brasil.

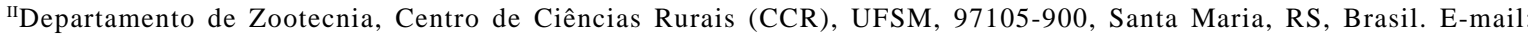
mgdarocha@gmail.com.*Autor para correspondência.

IIICurso de Zootecnia, CCR, UFSM, Santa Maria, RS, Brasil. 
utilizada para equilibrar o fornecimento de nutrientes, bem como aumentar a taxa de lotação da pastagem.

O fornecimento de suplementos pode apresentar interações positivas e negativas com o consumo de pasto, que constitui a fonte de alimento mais econômica para os animais em pastejo. Conhecer o consumo de forragem quando são fornecidas quantidades variáveis de suplemento pode ser útil para prever o desempenho animal e assegurar práticas de manejo alimentar que sejam mais eficientes.

A utilização de óxido de cromo como marcador externo para estimativas de consumo de forragem com herbívoros em pastejo é uma técnica amplamente difundida e possui vantagens como o baixo custo, a relativa simplicidade dos procedimentos analíticos (MORENZ et al., 2006) e a fácil obtenção do marcador.

Este trabalho foi realizado com os objetivos de determinar o consumo de forragem por cordeiras em pastagem de milheto, sob diferentes níveis de suplemento, e relacionar esse consumo ao desempenho de cordeiras, às características estruturais e à composição química do pasto.

\section{MATERIAL E MÉTODOS}

O experimento foi desenvolvido no período de novembro a abril, na Universidade Federal de Santa Maria (UFSM), situada na região denominada Depressão Central do Estado do Rio Grande do Sul. Os dados referentes às condições climáticas do período experimental foram coletados na estação meteorológica da UFSM (Departamento de Fitotecnia). A temperatura média no período experimental foi de $24,2^{\circ} \mathrm{C}$, com mínima de $18,8^{\circ} \mathrm{C}$ e máxima de $31^{\circ} \mathrm{C}$. A insolação média do período foi de 249 horas mensais e a precipitação pluviométrica de 103,3mm por mês.

O milheto (Pennisetum americanum (L.) Leeke) foi estabelecido em 25/11/05, com preparo mínimo do solo. A semeadura e a adubação foram realizadas a lanço, utilizando $30 \mathrm{~kg} \mathrm{ha}^{-1}$ de semente e $250 \mathrm{~kg} \mathrm{ha}^{-1}$ de NPK da fórmula 05-20-20, respectivamente. Em cobertura, foram adicionados $100 \mathrm{~kg} \mathrm{ha}^{-1}$ de nitrogênio, na forma de uréia, fracionados em três aplicações. Na área, existia um banco de sementes de papuã (Urochloa plantaginea) e poaia (Richardia brasiliensis), o que ocasionou a presença dessas espécies na pastagem.

Dezesseis cordeiras de seis meses e meio de idade (27,4 $\pm 3,6 \mathrm{~kg})$, cruzas Ile de France e Texel, foram distribuídas aleatoriamente na área experimental constituída de oito potreiros de aproximadamente 0,07ha. Quatro animais-teste por tratamento permaneceram em pastagem de milheto e receberam suplemento na proporção de $0,5 \%$ (S0,5), 1,0\% (S1,0) e $1,5 \%(\mathrm{~S} 1,5)$ do peso vivo (PV), enquanto que outras quatro cordeiras foram mantidas exclusivamente em pastagem de milheto (SS). O suplemento utilizado foi uma ração comercial (21,6\% PB; 19,7\% FDN; 86,9\% NDT), composta por farelo de arroz, farelo de trigo, farelo de soja, casca de arroz moída, calcário calcítico, fosfato bicálcico, cloreto de sódio e premix vitamínico mineral. Todas as cordeiras foram previamente submetidas a um período de adaptação de dez dias aos níveis de suplemento.

O método de pastejo foi o de lotação contínua com número variável de animais reguladores para manter a massa de forragem (MF), com valor aproximado de $2000 \mathrm{~kg} \mathrm{ha}^{-1}$ de MS. O pastejo foi diurno, entre $8 \mathrm{~h}$ e $17 \mathrm{~h}$, e o suplemento era fornecido diariamente às $17 \mathrm{~h}$ em baias individualizadas, localizadas dentro dos piquetes. Após 30 minutos, os animais eram retirados e as sobras eram recolhidas e pesadas. Todas as cordeiras tiveram acesso à água e suplementação mineral à vontade e permaneceram em abrigos no período noturno.

Para determinação da taxa de acúmulo de forragem (TAD, $\mathrm{kg} \mathrm{ha}^{-1} \mathrm{dia}^{-1} \mathrm{MS}$ ), foram usadas três gaiolas de exclusão ao pastejo por piquete e a MF, kg $\mathrm{ha}^{-1}$ de MS foi avaliada a cada dez dias por meio da técnica de estimativa visual com dupla amostragem. Nessa ocasião, a altura do dossel foi medida em 20 pontos por repetição. A forragem proveniente dos cortes da MF foi homogeneizada e dividida em duas subamostras: uma para determinação do teor de MS do pasto e outra para separação manual dos componentes botânicos e estruturais da pastagem. A partir dos valores obtidos após a pesagem dos componentes, foi determinada a participação de lâminas foliares e colmos (\%), bem como a relação proporcional entre eles (RFC).

A pesagem dos animais foi realizada no início do experimento e a cada 21 dias, com jejum prévio de sólidos e líquidos de 12 horas. Para o cálculo da taxa de lotação (TL, $\mathrm{kg} \mathrm{ha}^{-1}$ de PV), foi utilizado o somatório do peso médio dos animais-teste, com o peso médio dos animais reguladores multiplicado pelo número de dias que os mesmos permaneceram no piquete, divididos pelo número de dias do período. A oferta de forragem (OF, kg de MS 100kg de $\mathrm{PV}^{-1}$ ) foi calculada da seguinte forma: ((MF do período/número de dias+TAD/ TL)*100) e esse valor multiplicado pelo percentual de lâminas foliares na MF permitiu obter a oferta de lâminas foliares verdes (OLFV).

A simulação de pastejo foi realizada a cada 21 dias, pela coleta manual de uma amostra de forragem 
semelhante à consumida pelos animais-teste. As amostras foram pesadas, secas em estufa com circulação forçada de ar a $65^{\circ} \mathrm{C}$ por 72 horas, pesadas novamente e moídas em moinho tipo Wiley para análises do teor de proteína bruta pelo método de Kjeldahl (AOAC, 1990), da fibra em detergente neutro (ROBERTSON \& VAN SOEST, 1981) e da digestibilidade do pasto pelo método da fibra em detergente neutro indigestível (GOERING \& VAN SOEST, 1970).

Para a determinação do consumo, foi utilizado, como marcador externo, $1 \mathrm{~g}$ de óxido de cromo $\left(\mathrm{Cr}_{3} \mathrm{O}_{2}\right)$, fornecido aos animais-teste por via oral. Foram realizadas três determinações no decorrer do ciclo do milheto (13/02-22/02; 06/03-15/03; 28/03-06/04). Em cada determinação, o marcador foi fornecido diariamente, às $18 \mathrm{~h}$, por nove dias. A partir do sexto dia foi realizada a coleta parcial das fezes, a cada 12 horas, com o adiantamento de três horas a cada dia, de maneira que fosse obtida uma amostra a cada três horas no intervalo de 24 horas ao término dos quatro dias de coleta. O nível de cromo nas fezes foi determinado por espectrofotometria de absorção atômica (WILLIANS et al., 1962). O consumo de matéria seca (CMS) foi estimado pela fórmula: CMS=produção fecal/1digestibilidade) e a produção fecal (PF), em kg de MS $\mathrm{dia}^{-1}$, foi estimada por meio da fórmula: $\mathrm{PF}=$ cromo administrado (g dia-1)/cromo nas fezes ( $\mathrm{g} \mathrm{kg}^{-1}$ de MS) (POND et al., 1989). As taxas de substituição e de adição do consumo de suplemento sobre o consumo de forragem foram estimadas a partir do cálculo proposto por HODGSON (1990).

O delineamento experimental foi o inteiramente casualizado, com parcelas subdivididas no tempo, com quatro tratamentos e duas repetições de área. Os dados foram submetidos à análise de variância pelo procedimento GLM. Para a realização do teste de regressão polinomial em nível de 5\% de probabilidade, foi utilizada a transformação do tipo raiz quadrada para todas as variáveis testadas. As variáveis que não apresentaram interação significativa tratamento x período foram submetidas ao teste Tukey, em nível de 5\% de significância. Essas análises foram efetuadas com o auxílio do pacote estatístico SAS v.8.02 (2001).

\section{RESULTADOS E DISCUSSÃO}

Não houve interação níveis de suplemento $\mathrm{x}$ dias de utilização da pastagem para a massa de forragem (MF), a altura do dossel (ALT), os teores de proteína bruta (PB) e a fibra em detergente neutro (FDN) do pasto. Essas variáveis não diferiram entre tratamentos $(\mathrm{P}>0,05)$ e houve diferença entre os períodos de utilização da pastagem (Tabela 1) para a $\operatorname{MF}(\mathrm{P}<0,0001)$, ALT $(\mathrm{P}<0,0001)$ e $\mathrm{PB}(\mathrm{P}=0,0004)$.

Durante todo o ciclo do milheto, o valor médio da MF foi inferior aos 2000 $\mathrm{kg} \mathrm{ha}^{-1}$ de MS previstos no protocolo experimental. Existem divergências com relação ao valor de MF recomendado para o uso do milheto com ovinos: BRUM et al. (2008) usaram valores inferiores a $1000 \mathrm{~kg} \mathrm{ha}^{-1}$ de MS, enquanto CASTRO (2002) recomenda $3800 \mathrm{~kg} \mathrm{ha}^{-1} \mathrm{de}$ MS. A carga animal imposta para aumentar o perfilhamento e evitar o enlongamento precoce dos colmos do milheto promoveu também pisoteio excessivo e acentuada remoção de lâminas foliares. A fisiologia das plantas é profundamente afetada pela redução da capacidade fotossintética (LEMAIRE, 1997) e pela resistência ao pastejo e ao clima da estação.

A ALT foi diferente nos três períodos de utilização da pastagem $(\mathrm{P}<0,05)$, com redução de 65,5\% entre a primeira e a última avaliação. Alturas do dossel superiores a $20 \mathrm{~cm}$ não são eficientes para aumentar o ganho diário médio de ovinos (CASTRO, 2002) e valores superiores a esse só foram obtidos no primeiro período de utilização (Tabela 1).

Os teores de PB diferiram entre períodos de utilização, sendo mais elevados no final do ciclo do milheto (Tabela 1), provavelmente devido à participação da poaia (Richardia brasiliensis) na pastagem. PEDRINHO JUNIOR et al. (2004) observaram que essa espécie apresenta o ponto de máximo acúmulo de

Tabela 1 - Valores médios e desvio padrão, por período de utilização, para os descritores da pastagem de milheto para borregas sob diferentes níveis de suplementação.

\begin{tabular}{|c|c|c|c|c|}
\hline \multirow{2}{*}{ Itens } & \multicolumn{3}{|c|}{-------------------------Dias de utilização------------------------ } & \multirow{2}{*}{ Média } \\
\hline & $1-21$ & $22-42$ & $43-64$ & \\
\hline Massa de forragem ( $\mathrm{kg} \mathrm{ha}^{-1}$ de MS) & $1385,1^{b} \pm 252$ & $1351,4^{b} \pm 228$ & $1819,0^{\mathrm{a}} \pm 241$ & 1518,5 \\
\hline Altura do pasto $(\mathrm{cm})$ & $25,8^{\mathrm{a}} \pm 6,4$ & $18,7^{\mathrm{b}} \pm 7,3$ & $8,9^{c} \pm 3,6$ & 17,8 \\
\hline Proteína bruta (\%) & $18,2^{\mathrm{C}} \pm 0,2$ & $19,4^{\mathrm{b}} \pm 0,01$ & $22,3^{\mathrm{a}} \pm 0,3$ & 20,0 \\
\hline Fibra detergente neutro (\%) & $51,5 \pm 0,4$ & $45,1 \pm 7,1$ & $53,5 \pm 7,3$ & 50,0 \\
\hline
\end{tabular}

${ }^{a}$ Valores com sobrescritos diferentes em uma mesma linha são diferentes de acordo com o teste de Tukey $(\mathrm{P}<0,05)$. 
nitrogênio aos 145 dias após a emergência, o que coincide com o seu início de participação na composição botânica da pastagem. Em média, o conteúdo de $\mathrm{PB}$ na dieta foi de $360 \mathrm{~g} \mathrm{~PB} \mathrm{~kg}^{-1}$ de matéria orgânica digestível (MOD) e, quando o conteúdo de

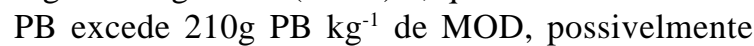
ocorrem perda de proteína, gasto energético excessivo pelos microorganismos ruminais e/ou transferência incompleta para o intestino delgado (POPPI \& MCLENNAN, 1995).

Os teores de FDN foram semelhantes durante todo o período experimental $(\mathrm{P}>0,05)$ e seu valor médio foi inferior ao valor de $60 \%$, que restringe o consumo de pasto pelos herbívoros (VAN SOEST, 1994).

Houve interação níveis de suplemento $\mathrm{x}$ dias de utilização da pastagem para oferta de lâminas foliares verdes (OLFV, $\mathrm{P}=0,017)$, relação folha : colmo (RFC, $\mathrm{P}=0$,0003), oferta de forragem (OF, $\mathrm{P}<0,0001)$ e taxa de acúmulo diário (TAD, $\mathrm{P}<0,0001)$.

A OLFV ajustou-se ao modelo quadrático de regressão somente no terço final do período experimental, sendo seu menor valor quando os animais receberam $0,74 \%$ do PV de suplemento ( $\hat{Y}=5,7-$ $\left.7,13 \mathrm{x}+4,76 \mathrm{x}^{2}, \mathrm{R}^{2}=0,74 ; \mathrm{P}<0,0001\right)$. A participação de lâminas foliares na pastagem foi de $24,13 \%$ da OF e contrasta com os dados de SCHWARTZ et al. (2003), que obtiveram quase a metade da OF composta por folhas. A RFC não se ajustou aos modelos de regressão testados $(\mathrm{P}>0,05)$, com valor médio de 0,31 $\pm 0,15$. Durante todo o período experimental essa variável esteve abaixo do valor 1,0, considerado crítico por PINTO et al. (1994), ocasionando a redução do consumo em função da alta quantidade de colmos (GENRO et al., 2004).

A OF (kg de MS 100kg de $\mathrm{PV}^{-1}$ ) e a TAD (TAD, kg ha-1 dia $^{-1} \mathrm{MS}$ ) não se ajustaram aos modelos de regressão testados para os dias um-21 de utilização do pasto e ajustaram-se ao modelo quadrático para os dias 22-64. Nos dias 22-42, as máximas OF $\left(\hat{Y}=10,17+29,06 x-15,87 x^{2} ; R^{2}=0,66 ; P=0,0016\right)$ e TAD $\left(\hat{Y}=60,71+410,36 x-209,45 x^{2} ; R^{2}=0,68 ; P=0,0028\right)$ ocorreram quando os animais receberam suplemento na proporção de $0,9 \%$ e $0,98 \%$ do PV. Nos dias que seguem até o final do experimento, o ponto de mínima $\mathrm{OF}\left(\hat{\mathrm{Y}}=16,25-14,33 \mathrm{x}+10,01 \mathrm{x}^{2} ; \mathrm{R}^{2}=0,87 ; \mathrm{P}<0,0001\right)$ е $\mathrm{o}$ ponto de mínima TAD $\left(\hat{\mathrm{Y}}=59,36-77,75 \mathrm{x}+63,04 \mathrm{x}^{2}\right.$; $\mathrm{R}^{2}=0,80 ; \mathrm{P}<0,0001$ ) ocorreram nos níveis $0,72 \%$ e $0,63 \%$ do PV de suplemento.

A TAD média de $119 \mathrm{~kg} \mathrm{ha}^{-1} \mathrm{dia}^{-1}$ de MS foi semelhante à média encontrada por outros autores (CASTRO, 2002; ROMAN et al., 2008). O crescimento do pasto, entretanto, deve-se principalmente ao acúmulo de matéria seca de colmo, em resposta ao deficit hídrico de 26,3\% em relação as normais climáticas dos últimos 30 anos.

A OF média, de 15,5\%, foi maior que a oferta necessária para maximizar o consumo de forragem por cordeiras, duas vezes superior às exigências de ingestão de MS sugeridas pelo NRC (2007). Ofertas de forragem maiores que esta proporção podem causar mudanças desfavoráveis na estrutura e na qualidade do pasto disponível, minimizando o consumo de forragem de animais suplementados (BARGO et al., 2003).

Houve interação níveis de suplemento $\mathrm{x}$ dias de utilização da pastagem para o consumo de forragem (pasto + suplemento). Os valores ajustaram-se ao modelo quadrático de regressão para os dias um-21 de utilização (Figura 1a) e o ponto máximo de ingestão de MS ocorreu quando as cordeiras receberam suplemento na proporção de $0,84 \%$ em relação ao PV. O consumo de forragem não se ajustou a nenhum modelo de regressão testado nos dias seguintes, até o final do período experimental.

O maior consumo de forragem situado entre os tratamentos S0,5 e S1,0 pode ser explicado pelo efeito aditivo do suplemento sobre a ingestão total de MS, de $96 \%$ e 99\%, respectivamente. Já no nível 1,5\% do $\mathrm{PV}$, para cada kg de MS do suplemento fornecido aos animais, $0,75 \mathrm{~kg}$ de pasto deixaram de ser ingeridos, caracterizando um grande efeito de substituição do consumo de pasto pelo consumo de suplemento. O consumo de forragem foi influenciado pelos níveis de suplemento somente no período 1 , provavelmente devido à altura do dossel, que teria sido limitante ao consumo de pasto (CASTRO, 2002).

As cordeiras consumiram, em média, 4,14\% do PV de MS dia ${ }^{-1}$, valor 52\% superior à ingestão de MS sugerida pelo NRC (2007) para essa categoria animal. Em Cordeiras Ile de France, em Panicum maximum JACQ., foi observado o valor médio de ingestão de MS de 2,59\% do PV de MS dia $^{-1}$, 37\% inferior ao consumo médio obtido no presente experimento (BARBOSA et al., 2003).

Houve interação níveis de suplemento $\mathrm{x}$ dias de utilização da pastagem para as variáveis ganho diário médio (GDM, $\mathrm{P}=0,038$ ), ganho de peso vivo por hectare (GPV, $\mathrm{P}=0,030$ ) e taxa de lotação (TL, $\mathrm{P}=0,0257$ ). Nenhuma dessas variáveis ajustou-se aos modelos de regressão testados para os primeiros 21 dias de utilização da pastagem $(\mathrm{P}>0,05)$.

O GDM aumentou linearmente em relação aos níveis de suplemento nos dias 22-42 de utilização da pastagem com um incremento de 59,7\% entre o nível zero e $1,5 \%$ de suplemento. Essa variável foi positivamente correlacionada com a OLFV nesse 


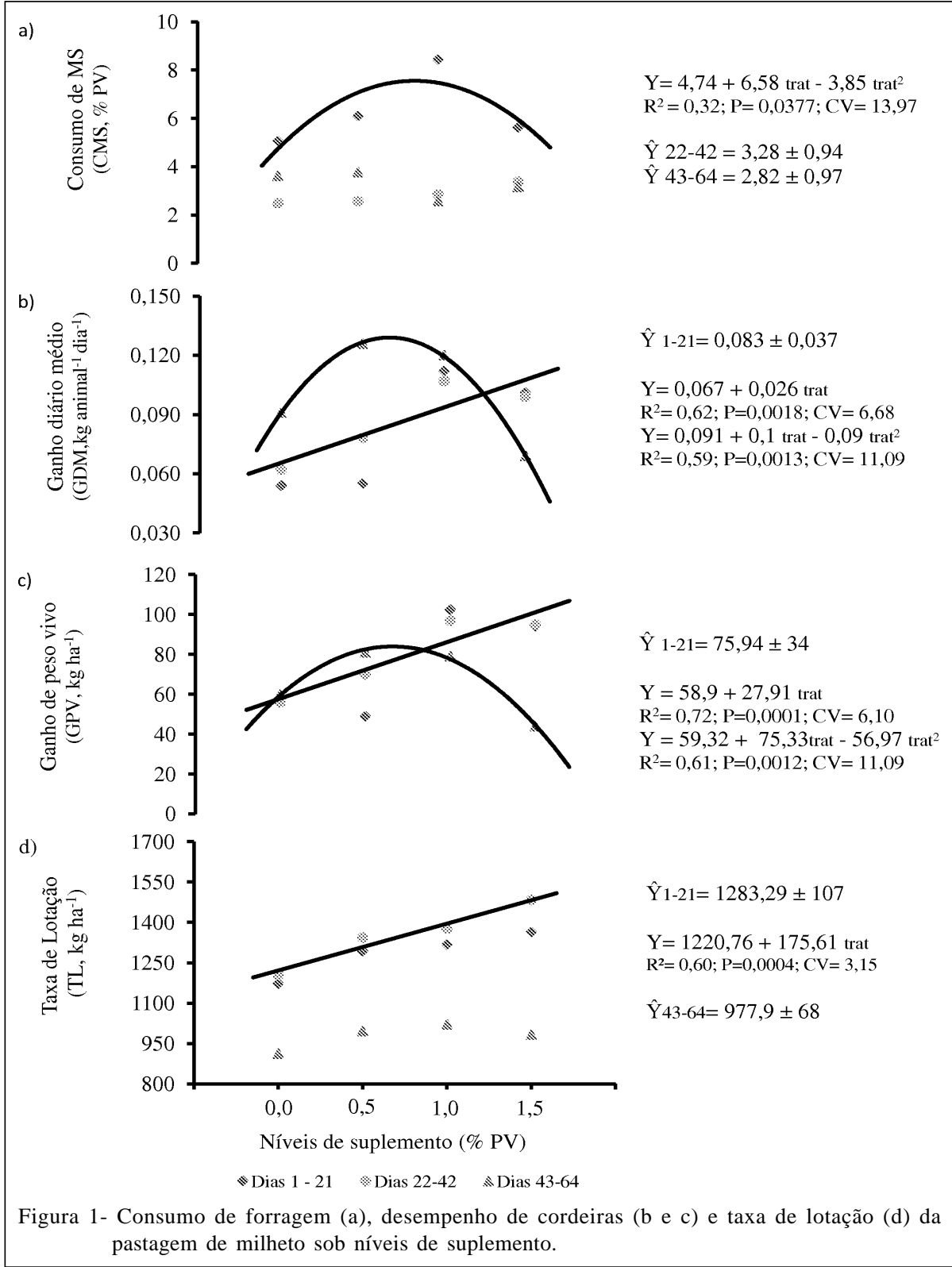

período ( $\mathrm{r}=0,75 ; \mathrm{P}=0,0021)$. Nos dias 43-64, o GDM ajustou-se ao modelo quadrático de regressão com aumento do ganho de peso das cordeiras até o nível 0,68\% do PV (Figura 1b). O ajuste do GDM a modelos distintos de regressão, nos períodos estudados, mostra que a mudança nas características estruturais do pasto (Tabela 1) interfere no padrão de desempenho das cordeiras em resposta aos níveis de suplemento.

O GPV teve um aumento linear, nos dias 2242 de utilização da pastagem, com incremento de 64,6\% entre o nível zero e o nível 1,5\% do PV (Figura 1c). A resposta em GPV decorrente do aumento de suplemento oferecido foi devida, provavelmente, à quantidade presente de lâminas foliares nesse período. Isso porque essa variável apresentou correlação positiva com a $\operatorname{OLFV}(\mathrm{r}=0,81 ; \mathrm{P}=0,0004)$. Também nos dias 43-64 o GPV foi condicionado pela presença de lâminas foliares na pastagem e ambos a OFLV e o GPV ajustaram-se ao modelo quadrático de regressão. Os maiores ganhos de PV ocorreram no nível 0,65\% do PV de suplemento (Figura 1c) e nesse período a OFLV foi menor quando a percentagem de suplemento foi de $0,74 \%$ do PV.

$\mathrm{O}$ incremento na taxa de lotação (TL) foi linear ao longo do segundo período de utilização da pastagem (dias 22-42, figura 1d), sendo que esse mesmo comportamento foi observado no terço inicial de 
utilização, com coeficiente de determinação da regressão de apenas 0,42 , considerado como pouco explicativo. No período 2, a TL mostrou correlação positiva com a OFLV ( $r=0,73 ; \mathrm{P}=0,0012)$ e com a TAD $(\mathrm{r}=0,73 ; \mathrm{P}=0,0014)$. É esperada a correlação positiva entre TAD e TL, pois o cálculo de ajuste de carga leva em consideração o acúmulo de forragem previsto na pastagem em cada período.

\section{CONCLUSÕES}

O desempenho de cordeiras e a produção por área em resposta a níveis variáveis de suplemento são condicionados ao estádio fenológico do milheto e à presença de lâminas foliares. No início da utilização do pasto, o nível 0,84\% do PV de suplemento determinou o máximo consumo de forragem (pasto+suplemento) pelas cordeiras, já no final do ciclo do milheto, o nível 0,66\% do PV proporcionou a melhor resposta produtiva, tanto individual quanto por área.

\section{REFERÊNCIAS}

ANUAlPeC. Anuário da Pecuária Brasileira. São Paulo: Instituto FNP, 2006. 369p.

ASSOCIATION OF OFFICIAL ANALYTICAL CHEMISTS AOAC. Official methods of analysis. 15.ed. Virginia: AOAC International, 1990. 1298p.

BARBOSA, C.M.P. et al. Consumo voluntário e ganho de peso de borregas das raças Santa Inês, Suffolk e Ile de France em pastejo rotacionado sobre Panicum maximum JACQ. CVS Aruana ou Tanzânia. Boletim de Indústria Animal. v.60, n.1, p.55-62, 2003.

BARGO, F. et al. Production and digestion of supplemented dairy cows on pasture. Journal of Dairy Science. v.83, n.1, p.1-42, 2003.

BRUM, M.S. et al. Sistemas de alimentação para a recria de ovinos a pasto: avaliação do desempenho animal e características da forragem. Ciência Rural, v.38, n.1, p.191-198, 2008.

CASTRO, C.R.C. Relações planta-animal em pastagem de milheto (Pennisetum ammericanum (L.) Leeke) manejadas em diferentes alturas com ovinos. 2002. $200 \mathrm{f}$. Dissertação (Mestrado em Zootecnia) - Universidade Federal do Rio Grande do Sul, Porto Alegre, RS.

GENRO, T.C.M. et al. Ingestão de matéria seca por ruminantes em pastejo. In: REUNIÃO ANUAL DA SOCIEDADE BRASILEIRA DE ZOOTECNIA, 41., 2004, Campo Grande. Anais... Campo Grande: SBZ, 2004. p.178-190.

GOERING, H.K.; VAN SOEST, P.J. Forage fiber analyses. Washington: ARS-USDA, 1970. 20p. (Agriculture Handbook, 379).

HODGSON, J. Grazing management. Science into practice. England: Longman Scientific \& Technical, 1990. 203p.
LEMAIRE, G. The physiology of grass growth under grazing: Tissue turn-over. In: SIMPÓSIO INTERNACIONAL SOBRE PRODUÇÃO ANIMAL EM PASTEJO, 1997, Viçosa. Anais... Viçosa: UFV, 1997. p.117-144.

MORENZ, M.J.F. et al. Óxido de cromo e n-alcanos na estimativa de consumo de forragem de vacas em lactação em condições de pastejo. Revista Brasileira de Zootecnia, v.35, n.4, p.1535-1542, 2006.

NRC - NATIONAL RESEARCH COUNCIL. Nutrient requirements of small ruminants. Washington: National Academy, 2007. 362p.

ROBERTSON, J.B.; VAN SOEST, P.J. The detergent system of analysis. In: JAMES, W.P.T.; THEANDER, O. (Eds.). The analysis of dietary fiber in food. New York: Marcel Dekker, 1981. p.123-158.

PEDRINHO JUNIOR, A.F.F. et al. Acúmulo de massa seca e macronutrientes por plantas de Glycine max e Richardia brasiliensis. Planta daninha, v.22, n.1, p.53-61, 2004.

PINTO, J.C. et al. Crescimento de folhas de gramíneas forrageiras tropicais, cultivadas em vasos, com duas doses de nitrogênio. Revista Brasileira de Zootecnia, v.23, n.3, p.327-332, 1994.

POND, K.R. et al. Passage of chromium-mordanted and rare earth-labeled fiber: time of dosing kinetics. Journal Animal Science, v.67, n.4, p.1020-1028, 1989.

POPPI, D.P.; McLENNAN, S.R. Protein and energy utilization by ruminants at pasture. Journal of Animal Science, v.73, n.1, p.278-290, 1995.

RIZO, L.M. et al. Desempenho de pastagem nativa e pastagem sobressemeada com forrageiras hibernais com ou sem glifosato. Ciência Rural, v.34, n.6, p.1921-1926, 2004.

ROMAN, J. et al. Características produtivas e estruturais do milheto e a sua relação com o ganho de peso de bezerras sob suplementação alimentar. Revista Brasileira de Zootecnia, v.37, n.2, p.205-211, 2008.

SANTOS, D.T. et al. Suplementos energéticos para recria de novilhas de corte em pastagens anuais. Desempenho animal. Revista Brasileira de Zootecnia, v.34, n.1, p.209-219, 2005.

SAS INSTITUTE. Statistical analysis user's guide. Version 8.2. Cary, 2001. 1686p.

SCHWARTZ, F. et al. Manejo de milheto (Pennisetum Americanum Leeke) sob pastejo de ovinos. Revista Brasileira Agrociência, v.9, n.2, p.151-155, 2003.

VAN SOEST, P.J. Plant, animal and environment. In: Nutritional ecology of the ruminant. 2 ed. Ithaca: Cornell University, 1994. p.77-92.

WILLIANS, C.H.; et al. The determination of chromic oxide in feces samples by atomic absorption spectrophotometry. Journal Animal Science, v.59, n.3, p.381-385, 1962. 